\title{
Reducing Free Riding Behaviour in Collaborative Work with Computer Supported Tools
}

\author{
Wieger Kloppenburg ${ }^{1}$, Eva Nurlatifah ${ }^{2}$, Christian Spijkerboer ${ }^{3}$, Fitri Almira Yasmin ${ }^{4}$ \\ ${ }_{1,2,3,4}$ University of Twente, Enschede, The Netherlands \\ 1'g.w.kloppenburg@student.utwente.nl, ${ }^{2}$ evanurlatifah@student.utwente.nl, ${ }^{3}$ e.c.spijkerboer@student.utwente.nl, \\ ${ }^{4}$ fitrialmirayasmin@student.utwente.nl
}

\begin{abstract}
Free riding behaviour is a problem that has been around for many years. With all the new technological advances, there is much more collaborative work supported by online tools. These developments make it easier for individuals to become a free rider. This research carried out a literature study, to find the best method to reduce free riding behaviour. Besides the methods, this study also elaborates some factors that trigger free riders in a group. The methods which are highlighted in this research are implementation of assessments, group awareness tools, sufficient group size and enhancing team morale. However, the study found that none of the methods cover all the aspects of free riding behaviour. It is suggested by this research to combine and improve various methods, to a new method that can effectively reduce free riding behaviour in collaborative work with computer supported tools.
\end{abstract}

Keywords- collaborative work, computer supported tools, free ride, social loafing, computer supported collaborative work

\section{INTRODUCTION}

Free riding is the behaviour of an individual in a group, who shares in the benefits of group work, but does not provide a proportional share of the costs to obtain those benefits. The person who displays free riding behaviour is called a "free rider" [1]. Free riding is sometimes also referred to as "social loafing"[2]. There is a slight difference between the two definitions. With social loafing, the individual exhibits a decrease in effort when working in a group, compared to working independently, which hurts both himself and the group [3]. Free riding is more seen as a cause for social loafing. A free rider puts in less effort, but still shares the benefits of the group, where it does not hurt the free rider [1].

With virtual groups being a component of the educational and corporate structure, free riding is put in a different perspective. Online group interaction is very complex. The most general problem is individual behaviour of free riding. Also, motivation, poor communication and task allocation are problems that occur in these virtual groups [4] [5] [6].
This research focuses on finding methods to free riding behaviour in a group structure context. To prevent confusion between collective work and group work, defining and understanding both terms is necessary. Most researchers consider a collective to be temporary in nature and consisting of many individuals with an unorganized group structure. A group is usually smaller in number, with a defined infrastructure, and more permanent in nature [7].

This work will help practitioners who want to know what factors can make free riding more accessible and which method is best to reduce free riding behaviour. By identifying methods found within the literature, this research gives methods and their factors to reduce free riding behaviour. Hopefully, this work identifies some methods to reduce it.

Therefore, the purpose of this research is to identify the best methods to reduce free riding behaviour in collaborative work with computer supportive tools. In chapter two problem statement, the research questions are given to give answer to the problem. In chapter three research method, the method to answers these questions is explained. In 
the chapter four, literature, will present the relevant subjects from the research questions and elaborate on these subjects using relevant literature. The research questions will be answered in chapter five conclusion. A summary will be given to answer the sub questions and from that the main research questions can be answered. The chapter six, discussion, will contain a discussion about the conclusion and the rest of the research.

As stated in the introduction, free riding is a big problem, but how can this problem be made smaller? This research gives an overview of the current methods to reduce free riding. The aim of this research is find methods to reduce free riding behaviour in collaborative work with computer supported tools. With this overview, a best method to reduce free riding is chosen, if such a method is found. To accomplish this, factors that make free riding more accessible are discussed and the consequences of free riding.

Research questions are created to define the scope of this research. The main research question is: What are the best methods to reduce free riding behaviour in collaborative work with computer supported tools?

To answer the main research question, three sub-questions need to be answered:

1. What factors make free riding more accessible?

2. How does free riding behaviour influence the performance of collaborative work?

3. Which methods can be used to reduce free riding in collaborative work with computer supported tools?

\section{RESEARCH METHOD}

This research is a literature study. The method used in this research is the cataloguing of relevant literature of the context. The context is free riding behaviour in collaborative work with computer supported tools. After finding this context, the initial literature was reviewed for factors that influence free riding and its consequences. Each team member wrote down a summary of their findings and elaborated on it in a team discussion. The initial literature review helped to construct the research questions and to determine the scope of this research. Then the research was used to answer the sub questions. These answers in turn helped to answer the main research question and give recommendations for future research.

\section{RESULT AND DISCUSSION}

A. LITERATURE

In this section, the relevant subjects for the research questions will be discussed. Definitions and explanations are given based on relevant literature. The definition of free riding itself is already given in the introduction, as: Free riding is the behaviour of an individual in a group, who shares in the benefits of group work, but does not provide a proportional share of the costs to obtain those benefits.

1. Factors for free riding behaviour

This section describes some factors that would make free riding more accessible. The focus will lie on free riding in groups that make use of computersupportive tools, but also free riding in general group work are discussed.

a. Group size

Albanese \& Fleet [1] state that increasing the group size will stimulate free riding behaviour in general. Three factors influence this behaviour: perceptibility, noticeability and individual share in the work. When groups are small, free riding is more noticeable. Increasing the group size could also bring an increase in the free riding behaviour, because monitoring all the other group members gets more difficult.

b. Dispersion

Dispersion is the situation where members of a team are located at different locations and communicate with help of computer supported tools [8]. According to McDonough teams who works on the same place outperform dispersed teams [9]. Dispersion will increase the free riding behaviour. The social influence of watching a group member performing a task is different from the influence of reading the online status or message of the group member. When members are identifiable, they are more likely to do more. If the members are anonymous or less identifiable, they will lose restraint and it is easier to free ride [10].

c. Group Awareness

According to Mullen [3], working individually on a collective task leads to a decrease of selfawareness. This will result in individuals not caring 
for the performance standards of the group and the commitment to the group work.

Unequal participation of group members also brings the risk of missing important and relevant information, because it becomes difficult to know what other team members have done. Van de Ven \& Delbecq [11] state that domination by a team member will lead to inefficient use of the time of the group. Members who talk more in the group will have a greater influence on the final product, this can lead to the fact that the other team members to display free riding behaviour.

d. Online Communication

While working in online groups, the communication and collaboration are more difficult than in face-to-face meetings. According to Piezon and Donaldson [4], the group interaction becomes a larger issue because of the physical separation, social isolation, and distance. Online group activities are harder to organize and more difficult to operate on a higher efficiency level. This will increase the opportunity to free ride, because nobody will be monitoring their contribution.

Weisband [12] assumes that distributed groups do not have the right information about the activities of their teammates over a longer period of time. The group members need to rely entirely on the messages what will appear on their computer or mobile phone screen, to know what the other members of the group are doing.

According to Chidambaram and Tung [13], social impact plays an important role in determining the contribution of the individuals. But the social performance, measured using group cohesiveness, did not differ between online and offline groups. They also stated that the social pressure on group members is higher when working face-to-face and they are more productive because they see each other.

e. Absence of Individual Assessment

Karau and Williams [14] state that the evaluation approach is one of the main factors that causes individuals to free ride when working collectively. The absence of individual assessment might lead to people thinking they can depend on more active team members to produce group outcome. Albanese \& Van Fleet [1] claim that when people think their supervisors are not aware of the individual effort in the group work, it becomes economically rational for the employees to display free riding behaviour.

f. Sucker Effect

One of the more devastating factors that stimulates an individual for showing free riding behaviour, is called the "sucker effect". The sucker effect is basically a downward spiral, that is triggered by the perception that group members are free riding. Sometimes the group members will "carry" the free rider, this is called "playing the sucker role"[15]. But to avoid playing the sucker, the individuals will reduce their own effort and participated in the free riding, which is called the sucker effect [16]. Hütter and Diehl [17] argue that team diversity and equity sensitivity have an effect on the sucker effect. If individuals are from a different social group, they are less likely to take on the sucker role. The same goes for people with a high equity sensitivity.

\section{Consequences of free riding}

The study of free riding and social loafing are considerably various. However, the literature about the consequences of free riding is sparse. Most of the literature focusses on what free riding is and how to prevent or overcome it. In an article by James Shepperd [18], free riding is one of the main cause of a productivity loss in group performance. Productivity loss could reduce the quality of the group outcomes or prolong the time needed to complete the group task. A capable individual in the group might decide to put in more than he got allocated, to fulfil the task or to complete the desired outcome.

Besides the consequences of free riding in group performance, there are other consequences that the team might face if one or more member(s) perform the free riding behaviour. These are explained in the next section.

\section{a. Sucker Effect}

According to a research done by Piezon [19] about free riding in online learning group describes that the main reason team member engages in sucker effect is equity. Group members will reduce their workload until they feel like their fair share of the load is equitable to that of others. So as a consequence of one individual's free riding behaviour, other team members will also start free riding [19]. 
b. Impedance of Team Cognition

This consequence is closely related to group awareness which has described as one of the factors of free riding. Based on the empirical research done by $\mathrm{He}[20]$, the scale of free riding in a group has deteriorating effects in team cognition, particularly in shared awareness of expertise location and shared task understanding. Shared awareness of the expertise location relates to the knowledge of expertise of each member. Shared task understanding relates to the understanding of the main task for each member. Cooke et al. [21] state that continual communication and working together is needed to develop those elements. Yet, free riding behaviour triggers individual members to avoid each other [1]. Therefore, He [20] concludes that free riding could scale down the team performance regarding the team cognition.

3. Methods to reduce free riding

This section describes possible methods to prevent or reduce the free riding behaviour in online collaborative work. These methods mostly are a result of a case study in the context of collaborative work.

a. Implementation of Assessments

There are two possible types of assessments that could be implemented to reduce free riding behaviour. These types include, but are not limited to, group peer assessments and collaborative processes and product assessments.

For a group peer assessment, team members perform peer assessments by filling in an evaluation form with a set of benchmarks defined by their supervisor. There are various types and structures for peer evaluations. Peer evaluation with feedback enhances the team members learning, as they are actively engaged in articulating evolving understandings of subject matter and it also enables them to better self-assess as some skills are common [22].

Another method for peer evaluation is suggested by Brooks \& Ammons [23]. They created an instrument characterized by early implementation, multiple evaluation points and the use of specific evaluative criteria. Druskat and Wolff [24] found that the dependent factor in group assessment is timing. They suggested that evaluations should be made at the same time tasks are divided and roles are claimed. According to Fiechtner and Davis [25], feedback will stimulate team members to improve at multiple stages. Thus, add multiple evaluation points in the project or course to improve team members. The last characteristic of this method is the specificity of the performance criteria. Harkins [26] states that team member performance is improving when individual work is evaluated to specific criteria.

However, literature suggests that the biggest problem with peer reviews is that team members are easily biased or not honest in giving feedback because of friendship, gender, race, interpersonal relationship, or personal likes and dislikes [27]. To tackle this problem, the use of anonymous peer assessment is suggested.

Collaborative products refer to the artefact that the group aims to achieve, while collaborative processes are the steps to achieve this. Collaborative processes and products assessment is typically performed by a supervisor, which is an external part of the team.

A qualitative case study that explored the role of assessment in online collaborative learning was conducted by Janet Macdonald. She highlighted the importance of collaborative processes and product assessment. In her research, she observed the implementation of assessments in two different UK Open University courses with specific optionality, group size, assessment regulation and tools used as its dependent variables. The result of the research shows that assessing collaborative processes and products encourages the participation of the student and supporting a growth in group confidence and cohesion [7].

Swaray [28] figured out that a designed learning process and assessment could effectively reduce the free riding problems in a group. He modified an assessment which encouraged members to actively participate in a group task. The level of contribution of each member was supervised. The assessments which are set in this research are the presentation, the report, the short answer in discussion and the reflective piece. Based on this research, $87 \%$ of the participants agreed that implementation of this method makes the free riding behaviour less utilized in a group [28].

Despite the possible improvement and advantages, online collaborative assessment could 
lead to a lack of flexibility created by the dependence on the group [7]. This is in contrast with the nature of online collaboration, which provides more possible collaboration with people in a different place and time. For example, in the online educational environment, online learners who seek flexibility in their study situations can view participation in group learning as an impediment to their progress. Often, they baulk at or at best tolerate, collaborative learning situations imposed by a course design [29].

The use of computer-supported tools simplifies the assessment processes, both collaborative products and processes assessment, as well as peer assessment. It supports transparency by providing a written record of the interactions between students [7]. The availability of the record enables the supervisor and team members to evaluate one's activity and contribution. The use of computer-supported tools also encourages team members to do the assessment. Considering it has a set deadline for assessment and it is easy to track which person who has not submitted theirs.

b. Group Awareness Tools

Group awareness consists of several elements. Knowledge and perception of who is there, where other persons are located, where they are looking at, and what they are doing [30]. Group awareness tools (GATs) provide group members with information about group members' opinions or knowledge regarding a topic or group members' participation rates [31]. The information improves the coordination of collaborative processes as one way of reducing the characteristic awkwardness of remote collaboration. It can reduce group members' efforts to coordinate their actions, can increase their efficiency, and reduce the chance of errors [30]. However, the effect of using GATs on coordination and collaboration was therefore indirect rather than direct. Using the tool increased social group awareness, which in turn affected how students coordinated their collaboration [31]. Therefore, the effectiveness of using a GAT depends on how the team member utilizes the tools.

\section{c. Sufficient Group Size}

Determining optimal group size in the team is crucial as it is affecting how the team members perceive their contribution and noticeability of free riding behaviour [1]. Piezon [19] suggest that the best rule of thumb is that a group should not be larger than the size require by the task. Hackman [32] specifically recommends a maximum number of six members for an educational group to limit the number of potential interactions between team members. He [20] also supports the idea of group size by mentioning that group size is an effective mean to prevent the free riding behaviour.

Even though smaller group sizes might prevent the free riding behaviour, a group consisting of more team member means the possibility of more variety of skills and opinions could improve the collaboration processes. Thus, it is sometimes difficult to determine how large or small a group should be to maximise performance without endangering productivity [19].

\section{d. Enhancing Team Morale}

Team Morale is defined as the collective attitude and shared commitment among members with regard to their team tasks [20]. When a team builds this morale in their group, the number of free riders will be lower. Team morale could effectively lessen the scale of free riding.

In addition, Piezon [19] points out several attitudes which relate to team morale. Attitudes, such as positive communication, role assignment and clear expectation. These attitudes could reduce the impact of free riding. Through her survey, participants believed that these attitudes potentially minimize the problems by optimizing communication between team members, helping each member to play their role, stay on the track and clarify the task achievements or goals of the team.

Grusky [33] describes morale as one of factor that determines group performance. But this will vary depending on the group settings. For example, the nature of the organisational setting, the rank of the position and the experience of the person.

\section{CONCLUSION}

In this chapter, the research questions of the paper are answered. First the three sub-questions are answered. These answers lay the foundation for the answer to the main research question at the end of this chapter. The first sub question consider which factors can make free riding more accessible. There are several factors for free riding in group work. First, group size, which is influenced by perceptibility, noticeability, and individual share in 
the work. Second and third, dispersion and online communication, the social influence of being watched is different than just reading an online message. Fourth, decrease of self-awareness, dominated people in the group will have a greater influence, what can lead to other team members will show the free riding behaviour. Fifth, absence of individual assessment, group members will rely on more active team members, because of the absence of individual assessment. Lastly sixth, the sucker effect, in which people will participate in free riding when group members are showing free riding behaviour.

Moving on to the impact of free riding behaviour, the decreasing of team performance is the main consequence of free riding behaviour. It is perceived by the presence of the sucker effect which triggers people to play the sucker role. Another factor is the impedance of team cognition which affects the group awareness.
Then, for the third sub question, several methods to counter free riding behaviour in a group work were found. The first method is implementing assessment such as peer assessment and assessment of collaborative work. The second method are group awareness tools, which can help the members in coordination between each other. Sufficient group size is the third. The last one is to the use of enhancing the team morale to reduce free riding behaviour. Each of those methods have their own characteristics to counter free riding behaviour. These methods also give some recommendations for implementing the method. Table 1 provides an overview of all these methods. But there are no methods that actually cover all the free riding motives and consequences for collaborations with computer supported tools.

\begin{tabular}{|c|c|c|c|c|}
\hline Solutions & Factors & $\begin{array}{l}\text { Methods to reduce free } \\
\text { Advantages }\end{array}$ & $\begin{array}{l}\text { Disg benavlour } \\
\text { Disantages }\end{array}$ & $\begin{array}{l}\text { Recommendations } \\
\text { for implementation }\end{array}$ \\
\hline Peer assessment & $\begin{array}{l}\text { Absence of individual } \\
\text { assessment }\end{array}$ & $\begin{array}{l}\text { Enhances student } \\
\text { learning [22] } \\
\text { Improves team } \\
\text { member } \\
\text { performance [26] }\end{array}$ & $\begin{array}{l}\text { Peers are easily } \\
\text { biased or not honest } \\
\text { in giving their } \\
\text { feedback [27] }\end{array}$ & $\begin{array}{l}\text { Anonymous online } \\
\text { peer evaluation, with } \\
\text { multiple evaluation } \\
\text { points and specific } \\
\text { evaluation criteria }\end{array}$ \\
\hline $\begin{array}{l}\text { Group } \\
\text { Awareness Tools } \\
\text { (GAT) }\end{array}$ & $\begin{array}{l}\text { Dispersion } \\
\text { Online } \\
\text { communication } \\
\text { Group Awareness }\end{array}$ & $\begin{array}{l}\text { Improves the } \\
\text { coordination of } \\
\text { collaborative } \\
\text { processes. } \\
\text { Increases the } \\
\text { efficiency, and } \\
\text { reduces the chance } \\
\text { of errors.[30] }\end{array}$ & $\begin{array}{l}\text { Indirect effect on } \\
\text { collaboration and } \\
\text { coordination. Teams } \\
\text { will depend on the } \\
\text { interpretation. [31] }\end{array}$ & $\begin{array}{l}\text { GAT will provide } \\
\text { group members with } \\
\text { collaboration } \\
\text { information (opinions, } \\
\text { knowledge, } \\
\text { participation) }\end{array}$ \\
\hline $\begin{array}{l}\text { Collaborative } \\
\text { processes and } \\
\text { products } \\
\text { assessment }\end{array}$ & $\begin{array}{l}\text { Absence of individual } \\
\text { assessment }\end{array}$ & $\begin{array}{l}\text { Encourages } \\
\text { student } \\
\text { participation and } \\
\text { supporting a } \\
\text { growth in group } \\
\text { confidence and } \\
\text { cohesion [7] [28] }\end{array}$ & $\begin{array}{l}\text { Could lead to a lack } \\
\text { of flexibility [7] }\end{array}$ & $\begin{array}{l}\text { Online learning } \\
\text { system with record of } \\
\text { group interaction, and } \\
\text { supports both task- } \\
\text { based and deliverable- } \\
\text { based evaluation }\end{array}$ \\
\hline $\begin{array}{l}\text { Sufficient Group } \\
\text { Size }\end{array}$ & Group size & $\begin{array}{l}\text { Affects how the } \\
\text { team members } \\
\text { perceived their } \\
\text { contribution and } \\
\text { noticeability of } \\
\text { free riding } \\
\text { behaviour [1] }\end{array}$ & $\begin{array}{l}\text { Difficult to } \\
\text { determine how large } \\
\text { a group should be to } \\
\text { maximise } \\
\text { performance without } \\
\text { sacrificing } \\
\text { productivity [19] }\end{array}$ & $\begin{array}{l}\text { Group size that is not } \\
\text { larger than the size of } \\
\text { the task requires }\end{array}$ \\
\hline Team Morale & $\begin{array}{l}\text { Online } \\
\text { communication Group }\end{array}$ & $\begin{array}{l}\text { Optimize the } \\
\text { communication }\end{array}$ & $\begin{array}{l}\text { Will vary depending } \\
\text { on the group settings }\end{array}$ & $\begin{array}{l}\text { Team morale includes } \\
\text { collective attitudes, }\end{array}$ \\
\hline
\end{tabular}


awareness within the group

and clear task

sharing. [19] commitments and

goals, role assignment
With the answers found to the sub-questions, the main research question can be answered: "What are the best methods to reduce free riding behaviour in collaborative work with computer supported tools?". Table 1. shows multiple methods to reduce free riding in group collaborations. But there are not yet methods that focus on all the factors and consequences found in sections 1 and 2. The methods that were found, only focus on one or two of the factors. Some of these factors overlap with free riding behaviour in general, not focussed on online collaboration. Two methods focus on reducing free riding behaviour with online communication. When trying to answer the main research question, it was found that there is not yet a complete method that focuses on online collaboration and touches all the factors and consequences that were found.

If a method had to be chosen, the group awareness tools touched the most factors. They improve the coordination of collaborative processes and increase the efficiency of the group. But the methods are free for interpretation. It depends on the team how the methods will be used and how effective they will be.

Peer assessments are also very useful to avoid free riding. They give individuals more incentive to put in more effort. But the peers are easily biased or not honest. Together with group awareness tools and well thought out group sizes, they could be combined to a great method to reduce free riding. Chapter 6, discussion will elaborate some more on this.

As shown by the conclusion, it was complicated to find a single best method to reduce free riding behaviour. Particularly a method for collaborative work supported by computer tools. We hoped that we could contribute to this research field,

\section{REFERENCES}

[1] R. Albanese, D. D. Van Fleet, R. Albanese, and D. D. V. A. N. Fleet, "Linked references are available on JSTOR for this article : Rational Behavior in Groups : The Free Riding Tendency1," vol. 10, no. 2, pp. 244-255, 1985.

[2] J. Suleiman and R. T. Watson, "Social loafing in by giving an overview of all the methods to reduce free riding behaviour. We have done that, but we could not give a best method, because there isn't one in our opinion. Multiple papers write about methods that look very similar, but with a different implementation. As said in the conclusion, solution could be to combine some methods (see table 1) into one method. The aim of this method is to reduce the free riding behaviour in collaborative work with the use of computer supported tools. The advantage this method would give, is that there is less room for interpretation of the multiple methods. Also, the focus should be more on collaboration with computer supported tools. Some of the methods for face-to-face collaboration could work for online collaboration, but they should be more specific. In the literature review, not enough methods could be found.

Inevitably, this research has some limitations. We focussed on finding the factors that influence free riding, the impacts, and counteract method related to group work supported by computer tools. It was difficult to find enough literature according to free riding in combination with technology or computer supported tools. Most methods can be applied for reducing free riding behaviour in general group work. We think these methods could also be useful for group work with computer supported tools, but they have to tweaked to be really useful.

So, for further research, we suggest focusing on developing a method to counter the factors that would free riding more accessible in collaborative work supported by computer tools. This method should be tested as a case study to validate that it actually reduces free riding behaviour in collaborative work with computer supported tools.

technology-supported teams," Comput. Support. Coop. Work, vol. 17, no. 4, pp. 291-309, 2008.

[3] B. Mullen, "Operationalizing the effect of the group on the individual: A self-attention perspective," J. Exp. Soc. Psychol., vol. 19, no. 4, pp. 295-322, 1983.

[4] S. L. Piezon and R. L. Donaldson, "Online Groups and Social Loafing: Understanding Student Group Interactions," Online J. Distance Learn. 
Adm., vol. 8, no. 4, 2005

[5] Steiner, Group Processes and Group Productivity, Academic. New York, 1972.

[6] B. Nonnecke and J. Preece, Silent Participants: Getting to Know Lurkers Better. London: Springer, 2003.

[7] J. MacDonald, "Assessing online collaborative learning: Process and product," Comput. Educ., vol. 40, no. 4, pp. 377-391, 2003.

[8] O. A. Alnuaimi, L. P. Robert, and L. M. Maruping, "Team Size, Dispersion, and Social Loafing in Technology-Supported Teams: A Perspective on the Theory of Moral Disengagement," J. Manag. Inf. Syst., vol. 27, no. 1, pp. 203-230, 2010.

[9] E. F. McDonoughIII, K. B. K. B. Kahn, G. Barczak, and E. F. McDonough, "An investigation of the use of global, virtual, and colocated new product development teams," J. Prod. Innov. Manag., vol. 18, pp. 110-120, 2001.

[10] R. Postmes, Tom., Spears, "Deindividuation and anti-normative behaviour: A meta-analysis.," Psychol. Bull., no. 123, pp. 238-259, 1998.

[11] A. H. Van de and A. L. Delbecq, "The Effectiveness of Nominal, Delphi, and Interacting Group Decision Making Processes.," Acad. Manag. J., vol. 17, no. 4, pp. 605-621, 1974.

[12] S. W.-D. work and undefined 2002, "Maintaining awareness in distributed team collaboration: Implications for leadership and performance," books.google.com.

[13] L. Chidambaram and L. L. Tung, "Is out of sight, out of mind? An empirical study of social loafing in technology-supported groups," Inf. Syst. Res., vol. 16, no. 2, pp. 149-168, 2005.

[14] S. Karau and K. Williams, "Social loafing: Research findings, implications, and future directions," Curr. Dir. Psychol. Sci., vol. 4, no. 5, pp. 134-140, 1995.

[15] S. Piezon, "Social loafing and free riding in online learning groups," 2011.

[16] N. Kerr, "Motivation losses in small groups: A social dilemma analysis.," psycnet.apa.org, 1983.

[17] M. Hütter and M. Diehl, "Motivation losses in teamwork: The effects of team diversity and equity sensitivity on reactions to Free-Riding," $G r$. Process. Intergr. Relations, vol. 14, no. 6, pp. 845-856, 2011.

[18] J. Shepperd, "Productivity loss in performance groups: A motivation analysis.," psycnet.apa.org, 1993.

[19] S. L. Piezon, "THE FLORIDA STATE UNIVERSITY COLLEGE OF EDUCATION By
JOI PHELPS WALKER A Dissertation submitted to the School of Teacher Education in partial fulfillment of the requirements for the degree of Doctor of Philosophy Degree Awarded : Spring Semester, 2011," 2011.

[20] J. He, "Counteracting Free-Riding With Team Morale - An Experimental Study," J. Internet Bank. Commer., vol. 17, no. 1, 2012.

[21] N. Cooke, E. Salas, P. Kiekel, ... B. B. factors that drive process and, and U. 2004, "Advances in measuring team cognition," cerici.org, 2004.

[22] N.-F. Liu and D. Carless, "Peer feedback: the learning element of peer assessment," Teach. High. Educ., vol. 11, no. 3, pp. 279-290, Jul. 2006.

[23] C. M. Brooks and J. L. Ammons, "Free Riding in Group Projects and the Effects of Timing, Frequency, and Specificity of Criteria in Peer Assessments," J. Educ. Bus., vol. 78, no. 5, pp. 268-272, 2003.

[24] V. U. Druskat and S. B. Wolff, "Effects and timing of developmental peer appraisals in selfmanaging work groups.," psycnet.apa.org, vol. 84, 1999.

[25] B. L. Smith and J. T. MacGregor, "What is collaborative learning?," Collab. Learn. A Sourceb. High. Educ., no. 1, pp. 10-30, 1992.

[26] SG Harkins, "Social loafing and social facilitation," J. Exp. Soc., 1987.

[27] R. Lu, "Anonymity in collaboration: anonymous vs. identifiable e-peer review in writing instruction," 2011.

[28] R. Swaray, "An evaluation of a group project designed to reduce free-riding and promote active learning," Assess. Eval. High. Educ., vol. 37, no. 3, pp. 285-292, 2012.

[29] J. Brindley, L. Blaschke, and C. Walti, "Creating effective collaborative learning groups in an online environment," irrodl.org, 2009.

[30] C. Gutwin and S. Greenberg, "A Descriptive Framework of Workspace Awareness for RealTime Groupware," Comput. Support. Coop. Work, vol. 11, no. 3-4, pp. 411-446, Sep. 2002.

[31] J. Janssen and D. Bodemer, "Coordinated Computer-Supported Collaborative Learning: Awareness and Awareness Tools," Educ. Psychol., vol. 48, no. 1, pp. 40-55, 2013.

[32] J. Hackman, "Leading teams: Setting the stage for great performances," 2002.

[33] O. Grusky, "Managerial Succession and Organizational Effectiveness," Am. J. Sociol., vol. 69, no. 1, pp. 21-31, Jul. 1963. 